\title{
Correction to: Synthesis of Plant Latex Based Hybrid Nanocarriers Using Surfactants for Curcumin Delivery
}

\author{
Antony V. Samrot ${ }^{1} \cdot$ K. Sahiti $^{1} \cdot$ Karanam Sai Bhavya $^{1} \cdot$ B. Suvedhaa ${ }^{1}$
}

Published online: 17 December 2018

(C) Springer Science+Business Media, LLC, part of Springer Nature 2018

\section{Correction to: Journal of Cluster Science}

https://doi.org/10.1007/s10876-018-1472-5

The original version of the article unfortunately contained an error in Fig. 8.

The correct view of Fig. 8 is shown in this erratum as follows. 
Fig. 8 Characterization by AFM

for nanocarriers synthesized

using latex of Euphorbia

antiquorum a unloaded

nanocarrier synthesised using

SPAN 20, b curcumin loaded

nanocarrier synthesised using

SPAN 20, c unloaded

nanocarrier synthesised using

TWEEN 20, d curcumin loaded

nanocarrier synthesised using

TWEEN 20, e unloaded

nanocarrier synthesised using

SDS, $\mathbf{f}$ curcumin loaded

nanocarrier synthesised using

SDS, g unloaded nanocarrier

synthesised using CTAB,

h curcumin loaded nanocarrier

synthesised using CTAB,

i unloaded nanocarrier

synthesised using Triton $\mathrm{X}$,

j curcumin loaded nanocarrier

synthesised using Triton $\mathrm{X}$
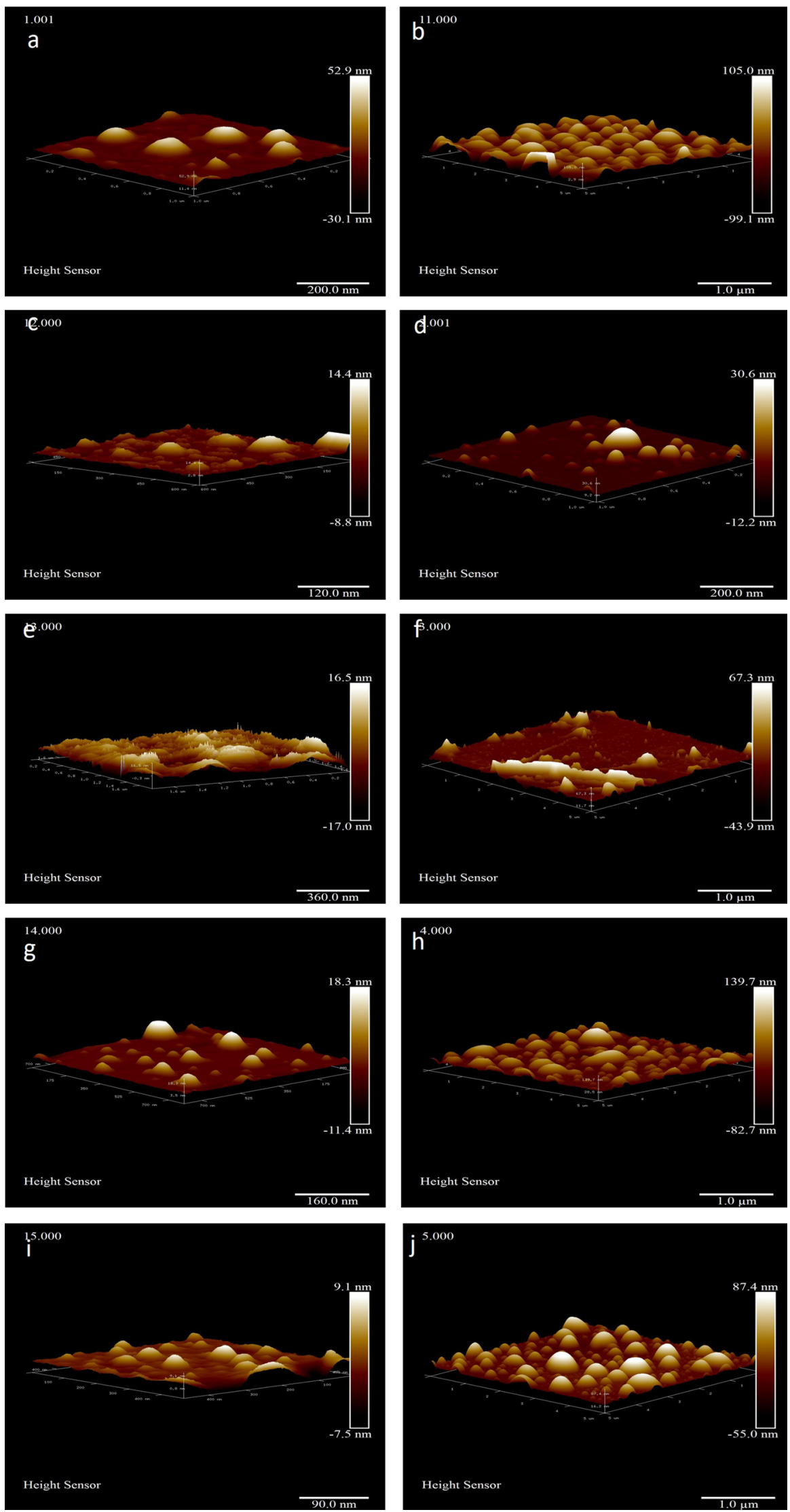